\title{
Stability Analysis of Shallow and Bias Loess Tunnel Based on Finite Difference Method
}

\author{
LiYongbing $^{1}$, LiBinglei ${ }^{2 *}$, HuaGuanyu ${ }^{1}$, JiaXinran $^{1}$, ChenYanqiao ${ }^{1}$, ZhangTianzeng $^{1}$ \\ ${ }^{1}$ College of Safety Engineering, Henan University of Engineering, Zhengzhou 451191, China \\ ${ }^{2}$ College of Zijin Mining, Fuzhou University, Fuzhou 350116, China
}

\begin{abstract}
Based on the Mohr-Coulomb elastic-plastic model and the practical engineering background of Mopanshan tunnel, this paper applies the finite-difference software FLAC3D to simulate and analyse the whole process of loess tunnel construction. Then, it analyses the stability of the surrounding rock and support structure after partial excavation of the loess tunnel under the shallow burying and unsymmetrical loading condition. The study showed that in the absence of support, the shear failure occurred to the top/upper pilot tunnel of the tunnel face, the failure zone under tensile stress happened to the shallow soil of the earth surface, and the soil of tunnel face appeared to be damaged. Finally, according to the analysis results, a reasonable construction method suitable for the shallow and bias loess tunnel is determined.
\end{abstract}

\section{Instroduction}

In view of the continuous emergence of largesection shallow burying loess tunnels, there has been more demands for the guides with engineering practice based on the rock mechanics and technical performance of the construction process [1]. Besides, due to the special complexity of large-section tunnels and dynamic construction process, few special experiments or numerical studies have been conducted on this now [2]. Therefore, based on the Mohr-Coulomb elastic-plastic model and the actual engineering background of the Mopanshan tunnel, this paper applies the finite-difference software FLAC3D to simulate and analyse the whole process of the loess tunnel construction [3].

\section{Basic equations of FDM}

The difference method in elastic mechanics is the theoretical basis for establishing the finite difference equation [4]. As shown in Fig. 1, two groups of parallel lines that are equally spaced and parallel to the coordinate axis are divided into grids on the elastic body. Given that $\mathrm{f}=\mathrm{f}(\mathrm{x}, \mathrm{y})$ is the continuous function in the elastic body, it may be one certain stress component or displacement component. This function, on one grid line parallel to the axis, e.g., 3-0-1 in Fig. 1, changes only with the $\mathrm{x}$ coordinates

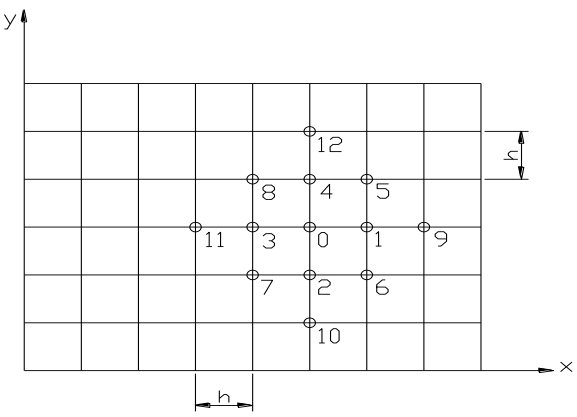

Figure 1. Finite difference grid

At neighbouring node 0 , the function $\mathrm{f}$ can be expanded to be Taylor series:

$$
f=f_{0}+\left(\frac{\partial f}{\partial x}\right)_{0}\left(x-x_{0}\right)+\frac{1}{2 !}\left(\frac{\partial^{2} f}{\partial x^{2}}\right)_{0}\left(x-x_{0}\right)^{2}+\frac{1}{3 !}\left(\frac{\partial^{3} f}{\partial x^{3}}\right)_{0}\left(x-x_{0}\right)^{3}+\cdots
$$

At node 3 and node 1 , $\mathrm{x}$ is respectively equal to $\mathrm{x} 0$ - $\mathrm{h}$ and $\mathrm{x} 0+\mathrm{h}$, i.e., $\mathrm{x}-\mathrm{x} 0$ equal to $-\mathrm{h}$ and $\mathrm{h}$ respectively. Bringing it into (1), it's calculated as:

$$
\begin{aligned}
& f_{3}=f_{0}-h\left(\frac{\partial f}{\partial x}\right)_{0}+\frac{h^{2}}{2}\left(\frac{\partial^{2} f}{\partial x^{2}}\right)_{0}-\frac{h^{3}}{6}\left(\frac{\partial^{3} f}{\partial x^{3}}\right)_{0}+\ldots \\
& f_{1}=f_{0}+h\left(\frac{\partial f}{\partial x}\right)_{0}+\frac{h^{2}}{2}\left(\frac{\partial^{2} f}{\partial x^{2}}\right)_{0}+\frac{h^{3}}{6}\left(\frac{\partial^{3} f}{\partial x^{3}}\right)_{0}+\ldots
\end{aligned}
$$

Assuming that $h$ is sufficiently small, its third power and the higher power can be ignored, and then (2) and (3) are reduced to: 


$$
\begin{aligned}
& f_{3}=f_{0}-h\left(\frac{\partial f}{\partial x}\right)_{0}+\frac{h^{2}}{2}\left(\frac{\partial^{2} f}{\partial x^{2}}\right)_{0} \\
& f_{1}=f_{0}+h\left(\frac{\partial f}{\partial x}\right)_{0}+\frac{h^{2}}{2}\left(\frac{\partial^{2} f}{\partial x^{2}}\right)_{0}
\end{aligned}
$$

Simultaneously solving (4) and (5), the difference formula is given as:

$$
\begin{aligned}
& \left(\frac{\partial f}{\partial y}\right)_{0}=\frac{f_{2}-f_{4}}{2 h} \\
& \left(\frac{\partial^{2} f}{\partial y^{2}}\right)_{0}=\frac{f_{2}+f_{4}-2 f_{0}}{h^{2}}
\end{aligned}
$$

Formulas (4) to (7) are basic difference equations, from which other difference equations can be derived.

It should be noted that the finite-difference method does not only limit the rectangular grid. Willkins proposed in 1964 [5] one finite difference method for deriving any shape element. Similar to the finite element method, the element boundary of finite difference method can be presented in any shape, and any element can have different properties and values.

\section{Establishment of numeral calcula- tion model}

In the design, the excavated section size for the shallowburied section of Grade $\mathrm{V}$ surrounding rock in Mopanshan Tunnel is: $14.9 \mathrm{~m} \times 11.2 \mathrm{~m}$ (width $\times$ height), including the reserved deformation of $25 \mathrm{~cm}$. According to engineering experience, taking the scope of construction impact into consideration, the basic dimensions of the model was determined as follows: for the excavation section, take 4 times the width from the tunnel centre line on the left and right side; take 3 times the distance from the tunnel to its bottom downward; take the distance from tunnel to the earth surface upward; the simulated tunnel mileage is $60 \mathrm{~m}$ long ( $\mathrm{LK} 1+970$ to LK2+030). Due to the artificial extraction of soil on the surface of the tunnel, a pit of about $10 \mathrm{~m}$ in depth was formed in the local section before the tunnel was excavated. The original state of the ground surface should be restored before excavation of the simulated tunnel, and then the redistribution of ground stress should be simulated when the surface is destroyed.

After original surface condition was restored, the dimensions (length $\times$ width $\times$ height) of the model were $60 \mathrm{~m} \times 114 \mathrm{~m} \times 43 \mathrm{~m} \quad(\mathrm{LK} 2+030)$ and $60 \mathrm{~m} \times 114 \mathrm{~m} \times 49 \mathrm{~m}$ (LK1+970). The number of model units was 41,840 . The model before and after surface destruction is shown in Fig. 2 and 3.

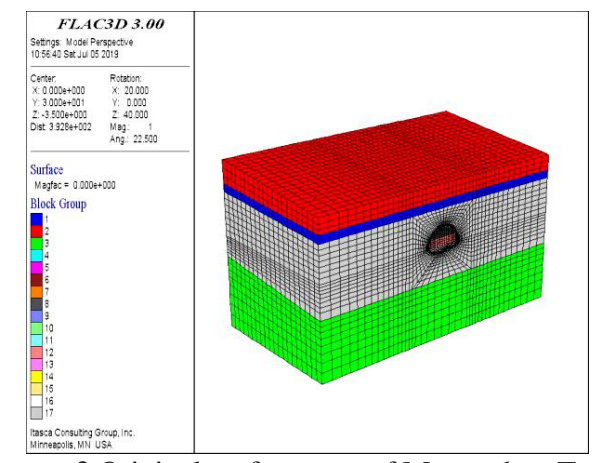

Figure. 2 Original surface map of Mopanshan Tunnel

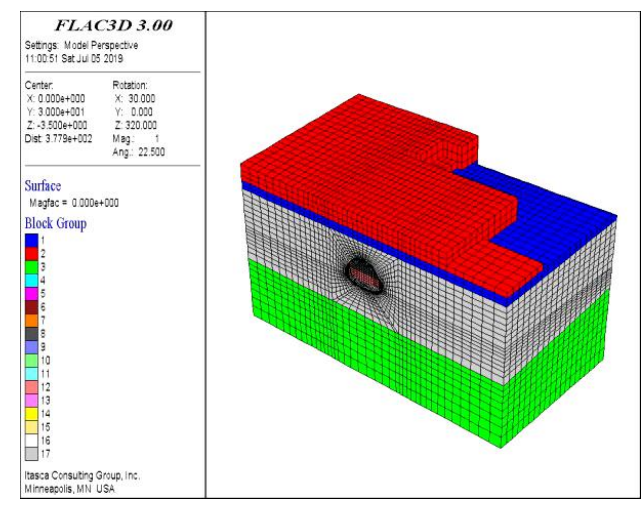

Figure. 3 Post-destructive surface map of Mopanshan Tunnel

The physical and mechanical parameters adopted for this calculation of each soil layer were taken from the results of the geotechnical tests conducted by the Hebei Provincial Transportation Planning and Design Institute; other physical and mechanical parameters of the tunnel were directly sampled from the construction site. See Table 1 for details.

Table 1: Numerical simulation parameters

\begin{tabular}{cccccc}
\hline Materials & $\begin{array}{c}E \\
(M P a)\end{array}$ & $\mu$ & $\begin{array}{c}\varphi \\
\left({ }^{\circ}\right)\end{array}$ & $\begin{array}{c}c \\
(\mathrm{kpa})\end{array}$ & $\begin{array}{c}\gamma \\
\left(\mathrm{kg} / \mathrm{m}^{3}\right)\end{array}$ \\
\hline Loess & 24 & 0.29 & 18 & 8.5 & 1480 \\
Fine sand & 60 & 0.22 & 32 & & 1760 \\
Sandy loam & 57 & 0.25 & 29 & 6.0 & 2020 \\
Rhyolite & 125 & 0.30 & 41 & 86 & 2460 \\
Anchor & 200000 & 0.25 & & & 7800 \\
$\begin{array}{c}\text { Primary sup- } \\
\text { port }\end{array}$ & 23000 & 0.21 & & & 1900 \\
\hline
\end{tabular}

\section{Numeral simulation results and analy- sis}

When the tunnel was driven from a symmetrical surface environment into the pit under unsymmetrical loading, and the slope of pit was vertical, the tunnel would receive a large bias when entering the pit. The distribution of soil layers around the pit and the position of the pit at the tunnel are shown in Figs. 4 and 5. 

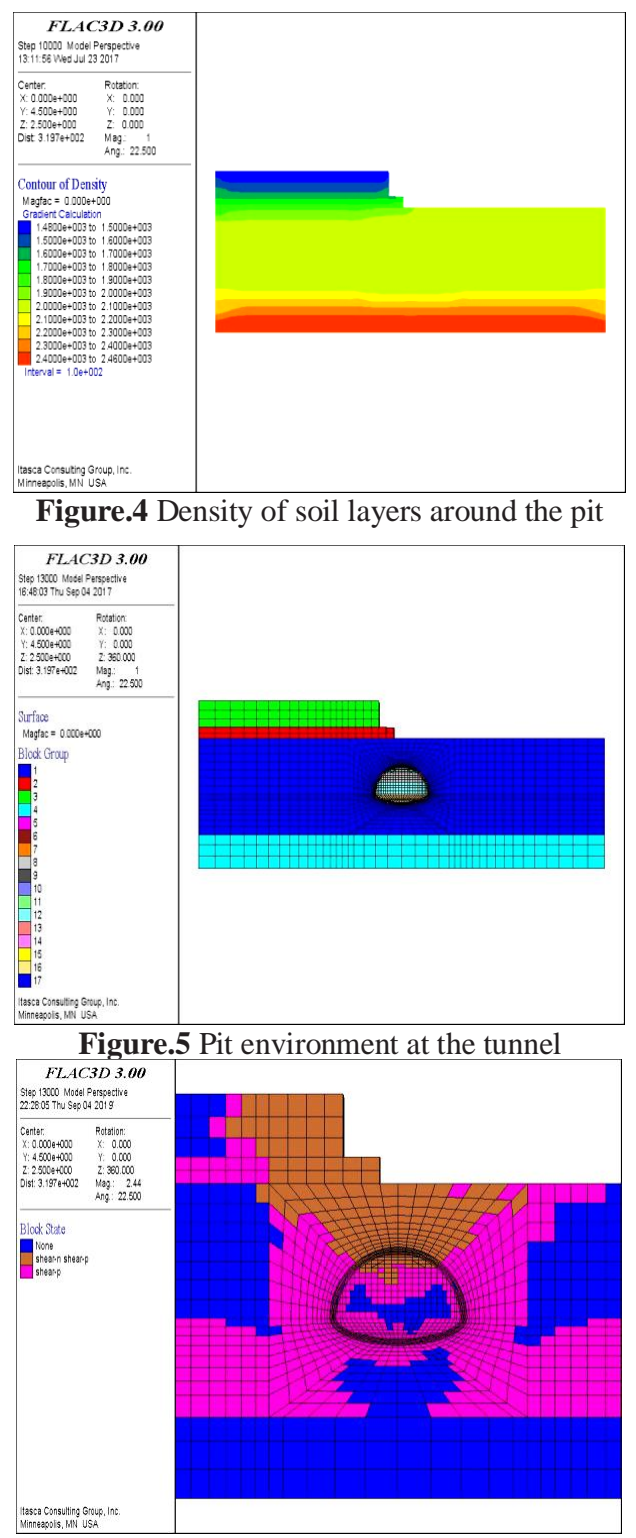

Fig. 6 Shear failure zone of tunnel without support

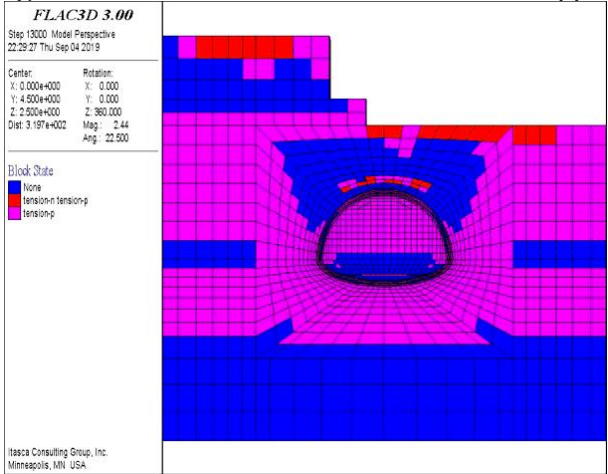

Fig.7 Tensile stress failure zone of tunnel without support

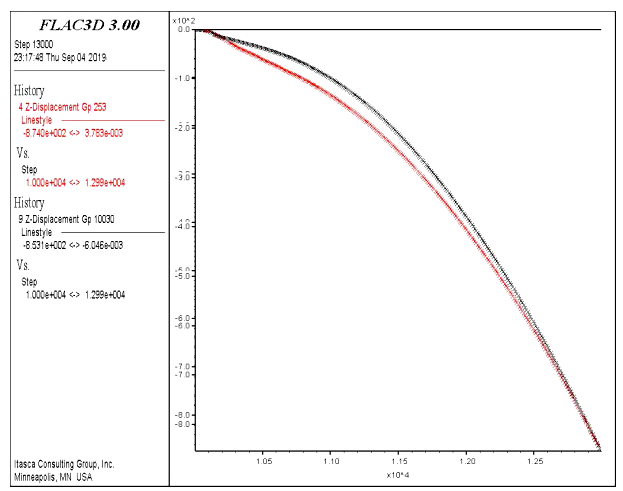

Fig.8 Subsidence curve of vault and ground surface without support

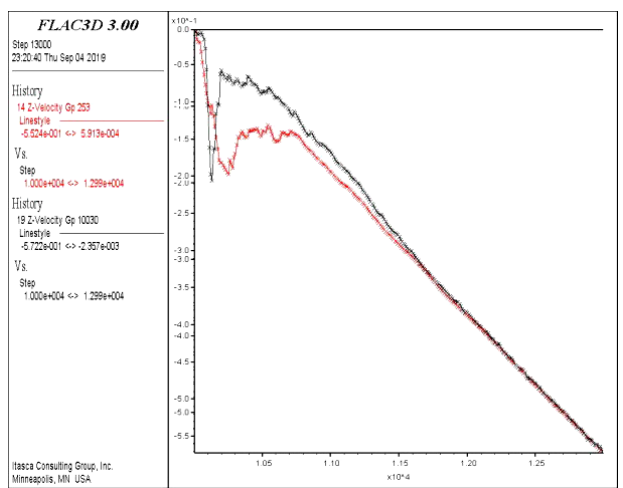

Fig.9 Subsidence rate of vaults and ground surface without support

As a result, there may be collapses at the vault and soil subsidence with cracks. The subsidence curve and rate of vault and ground surface in Fig. 8 and 9 show that their subsidence amount and rate are basically the same. Besides, through the numeral analysis in the figures, it can be seen that without support in tunnel, the subsidence of both vault and ground surface is over $80 \mathrm{~cm}$ and the subsidence rate increases, indicating that the soil in the tunnel face has been destabilized.

\section{Conclusions}

In this paper, the excavation and support of the tunnel were analysed with numerical simulation. The entire analysis process was verified to be in line with the actual situation, providing more accurate information on the surrounding rock and tunnel deformation for the construction of the tunnel project. The main conclusions are as follows:

(1) Through three-dimensional numerical simulation of the shallow buried bias section of the Mopanshan loess tunnel, the overall stability and mechanical response of the tunnel were evaluated after step-by-step excavation of the tunnel.

(2) Because of the unbalanced external force received by the tunnel support and the small bearing capacity of the loess tunnel foundation, the overall uneven deformation of the tunnel shall occur, and also the central part of core soil should be excavated first, to release the pressure on the left and right side, especially on the biased side.

(3) During the excavation process, more subsidence space should be reserved for the biased side with larger 
subsidence so as to further release the stress; when the tunnel is supported, the support for haunch on the biased side should be strengthened to reduce the difference of subsidence on the left and right side.

\section{Acknowledgements}

It is gratefully noted that the work is supported by the education scientific research project of youth teacher in the education department of Fujian province (No. JAT170068) 、 Project plan of key research projects in Henan higher education (No.17A560019) and Doctoral Foundation Project Number of Henan Institute of Engineering (No. D2016024).

\section{Reference}

1. Cundall, P. A., Strack, O. D. L. (1979): “A discrete numerical model for granular assemblies," Geotechnique, Vol.29, No.1, pp.47-47.

2. Swoboda, G., Moussa, A. (1994): "Numerical modeling of shotcrete and concrete tunnel linings," Tunnelling and Ground Conditions, pp.427-436.

3. Jiang, S. P., Hu, X. B. (2004): "The numerical analysis of constructional mechanical responses of Yangzong tunnel," Chinese Journal of Geotechnical Engineering, Vol.26, No.2, pp.178-181.

4. Zhao, W., Wu, S. C., Gao, Y. T., Zhou, Y., Xiao, S. (2015): "Numerical modeling and mechanical parameters determination of jointed rock mass," Journal of University of Science and Technology, Vol.37, No.12, pp.1542-1549.

5. Wilkins, M. L. (1964): "Fundamental Methods in Hydrodynamics. Methods in Computational Physics," New York:Academic Press, pp.211-263. 